\title{
Pachacuti.
}

\section{Mundo al revés}

\section{Pedro Trigo, \\ ITR, Caracas.}

\section{Introducción}

Las crónicas son el primer género de escritos que los españoles y oțos expedicionarios escribieron desde y/o sobre las tierras que se iban descubriendo, pacificando, es decir incorporando a la corona de Castilla, y poblando, o sea estableciendo una red de ciudades y villas de vecinos espanoles como cabeceras de los distintos reinos o señoríos indígenas, reducidos ellos mismos a vida ciudadana. El objetivo de las crónicas era ante todo justificar la conquista y colonización; legitimar la incoporación de las naciones indigenas a la corona de Castilla; glorificar a los conquistadores y encuadrar su gesta en los objetivos de la corona; y satisfacer la creciente curiosidad y las expectativas respecto de ese mundo que se revelaba por tantos aspertos inédito para los europeos hasta merecer para ellos el apelativo de nuevo: nuevo mundo, Nueva Espanta, Nueva Andalucía, Nueva Galicia, Nueva Granada.... Pero el objetivo más apremiante era justificar la conquista, cantóndola como gesta de un pueblo, fuente de gloria inmarcesible ante Dios y la historia. Sin embargo la conquista del Perú, con el desastroso colorón de la guerra civil, es un tanto atípica; además no contó con un político e ideólogo de la talla de Cortés, que supo convertir la masacre en necesidad histórica, ejecutada a contrapelo de la propia sensibilidad Por eso, junto a las crónicas más ideologizadas, hay otras más atentas a los hechos, en busca incluso de lecciones morales. Sin embargo, Guanán Poma escribe una Nueva Crónica. Es fácil de ver que la novedad no consiste sobre todo en las noticias, sino en la perspectiva. Por lo que toca a la conquista esto es evidente. Guamán supone las otras crónicas, presupone ya conocido el hilo de la historia Nosotros también lo presuponemos en nuestro estudio y asf analizamos la figura yue compone este escrito, sin meternos a considerar la exactiud de cada una de sus informaciones.

La crónica de la conquista es la crónica del mal gobiemo. Por una parte las desaveniencias entre Huáscar y Atahualpa que causaron tanta mortandad en el reino, cuya responsabilidad recae sobre todo en Huáscar porque, aun siendo él 
legítimo, por su carácter intratable no merecía ni era capaz de gobernar. Luego y sobre todo, que asi como los indígenas, dentro de su esquema de reciprocidad, se entregan, los espaffoles, enloquecidos por la fiebre del otro, no respetan a los donantes, sino que los saquean, agravian y al fin destruyen y asesinan. El colofón de este desorden absoluto, de este mundo al revés, donde nadie quiere conservar su puesto y las relaciones justas y debidas, es la guerra civil en la que los embajadores del rey de Castilla (que se hicieron asesinos de reyes y nobles y se convirtieron en conquistadores depredadores) pretendieron alzarse con el reino y se despedazaron unos a otros y desconocieron a su seffor natural y a sus representantes y así acabaron todos de mala muerte. Así pasaron estos afios de destrucción, ocasionados por no mantener el orden de las cosas y el puesto que cada quien tiene en ellas.

Pero si por crónica entendemos un relato cronológicamente ordenado de unos sucesos cuya secuencia temporal clara, precisa y coherente va haciendo ver causaciones subyacentes y, en el conjunto, un sentido general entrafiado en los mismos hechos, esta crónica no es tal sino una representación sacra. De ahf el tono retórico, impostado y el esquematismo efectista. La narración desde el principio hasta el final está jalonada por las coordenadas del nuevo orden: cada suceso aparece enmarcado por la cronología cristiana y por la de los regentes de este ciclo que serian el papa y el rey; así, la narración se quiebra constantemente, aparece sincopada; y se contrasta en cada caso el curso ordenado y estable de la cristiandad y del reino con los sucesos alocados del Perú, que se precipilan sin orden ni concierto hacia su mutua anulación y la consiguiente instauración del orden. En esta representación, los espafioles no tienen rostro ni caracteres: a todos posee por igual un frenesi desatado que les impide ser personas y comportarse como tales. Frente a ellos destaca, como representante del antiguo orden indígena, Atahualpa, lleno de majestades hasta en su abatimiento, y en su majestad, humano, con emociones encontradas, pero siempre con dignidad.

¿Dónde estaba Dios en este derrumbe? El autor destaca su ausencia, aunque también se hace presente.

\section{Los actores}

\subsection{Reciprocidad negativa}

El mal gobierno comenzó antes de la llegada de los espaftoles. A la muerte de Huayna Cápac, se desató una guerra civil entre sus dos hijos. Según el autor, Huáscar sería el legítimo y Atahualpa el bastardo. Huáscar que desde nifio "fue muy soberbio y mísero y mal inclinado, endacalas pajas mandaba matar a los dichos capitanes y asi huian de él" (386; ver 117). La "guerra duró treinta y seis afios" (386). El reino quedo dividido en dos partes: "desde Jauja hasla Quito y Novo Reino fue lo de Alagualpa y desde Jauja hasta Chile lo de Uáscar" (378). 
"Murieron muchos capitanes y soldados y se perdió muy mucha hacienda de los ingas y de los templos" (386). "En este tiempo salieron los hombres uiracochas cristianos en la revuelta de este reino" (378). Al enterarse de su llegada cada uno de los incas mandó a sus respectivos embajadores $(376,380)$. El reino estaba desangrado y sin unidad de acción, no pudo concentrar sus energías en comprender la novedad que se les venía encima y reaccionar frente a ella. Los espanoles llegaron, pues, en medio de la contienda, "y así fue conquistado y no se defendio" (386). Incluso estando Atahualpa preso habría mandado a sus capitanes "para que diese guerra y batalla a su hermano legítimo Uáscar Inga, y asf le venció y le prendio" y lo mataron, "porque había preguntado los cristianos del legítimo rey Inga, y asi lo mando malar" (389). Sumidos en el problema intestino, no calan en cuenta del peligro mortal en el que estaban y consumian sus energlas en dirimir su pleito en vez de unirse frente al invasor. Según el autor, Atahualpa sentenciaba a muerte a su hermano cuando estaba a punto de ser él mismo abandonado por los suyos y sentenciado a muerte.

En el recuento de los incas, el imperio parecía en su máximo apogeo: precisamente fue Guayna Cápac quien lo habría llevado a su máxima extensión territorial, pero además "edifico muchas ciudades y villas, aldeas y pueblos de indios y amojonó las tierras que dejó su padre" (114). El episodio de Huáscar (habria sido un incidente del que el imperio se hubiera repuesto sin mayores consecuencias o la estabilidad de las alianzas en las que ambos hermanos se apoyaron era un sintoma de que la desmesura y disparidad de los territorios los tomaba ingobermables? La repartición territorial entre ambos hermanos ltenia ciertas bases estructurales que podrian haber dado lugar a una división estable en mutua coordinación? El hecho fue que la guerra civil provoc6 una gran anarqula. "Y no habla justicia, andaba alborotada la tierra y se perdió todo" (114). Guamán habla basado la legitimidad de los incas en su capacidad para mantener un orden estable, justo y dinámico. Por eso echa la culpa de bodo a Huáscar: "por la soberbia ganó Uáscar tanto pleito y batalla y muerte, y fue causa de muerte de muchos sefiores principales y capitanes y de indios pobres, y destrucción de toda la riqueza de este reino" (117). En el sistema de reciprocidad de dones que constituye el sustrato ideológico del autor, la acción simbólica que expresarla esta soberbia suicida serfa que "habiendo querido y honrado su hermano bastardo Atagualpa Inga enviándole con su embajador presentes y riquezas respetíndole, le lomó de enviarle a su hermano Atagualpa vestido de mujeres y ollas (...) todo de mujer" (117). Asf, pues, aunque la legitimidad legal estaria en Huáscar, cosa que para el autor tiene mucha importancia para el hilo de la historia, la legitimidad espiritual correspondería a Alahualpa. Por eso, en él recsera la representación del mundo de los vencidos en este drama sagrado que comienza con una situación trágica: la reciprocidad negativa del insulto, de la guerra civil y "de robamiento de entre indios ellos propios" (114), es decir, de la anarquía 


\subsection{Oro y plata}

Los otros actores de este drama, los espafioles, parecen hipnotizados, enajenados, poseídos por una sola pasión. El aulor la describe con dos palabras que repite constantemente como un estribillo: oro y plata. Clamor de oro, plata, a eso quedan reducidos esos personajes en esta tragedia. Así se presentan desde el primer momento: aparece un espaftol perdido en las costas y lo levan al inca; éste le pregunta qué comía y el español por seflas "le apuntaba que comía de oro y plata, y asina dio mucho oro en polvo y plata" (370). En su sistema de reciprocidad de dones, el inca da al espaffol aquello de lo que y para lo que vive: oro y plata. La reciprocidad de este don es la conquista: matar a los donantes para arrebatar el don: "Con esta nueva más se alborotaron la tierra que si la reina les dejara venir me parece que todo Castilla se viniera con tan rica nueva deseada, oro y plata, que la gente andaba vestida toda de oro y plata y todo el suelo lo que pisaban era todo oro y plata macizo, que como piedra amontonaban oro y plata, aún hasta ahora dura aquel deseo de oro y plata y se matan los españoles y desuellan a los pobres de los indios, y por el oro y plata quedan ya despoblado parte de este reino, los pueblos de los pobres indios, por oro y plata" (372). Pizarro y Almagro armaron la expedición: "de hacienda pobre no quisieron traer nada sino ammas y escopetas, con la codicia de oro plata, oro y plata Indias, a las indias, Perú" (372). Las armas son el símbolo y a la vez el instrumenமo más drástico y radical del sistema de intercambio. Es la base del sistema. Aquí funciona no como horizonle de persuasión, sino estrictamente como valor de cambio: los espafioles dan lajos y balazos para conseguir oro y plata. Esto es posible porque es todo el país el que entra en trance y pierde así la cabeza y la sensibilidad moral. Pero, sin embargo, en medio de su locura guardan las formas que resultan terriblemente sarcásticas en el contexio: "en todo Castilla hubo graudes alborotos, era de día y de noche entre suefios, todo decía: Indias, Indias, oro plata, oro plata del Pení, hasta los músicos cantaban el romance: Indias, oro, plata, y se ajuntaron estos dichos soldados y mensaje del rey Nuestro Seffor católico de España y del Santo Padre Papa" (id.). ¿Qué significan tales mensajes? En el contexto no admiten otro sentido sino que ellos son las autoridades que están detrás de las armas y las bendicen, en definitiva las bocas insaciables de oro y los sacerdotes del oro. No se trataría de un sistema de reciprocidad de dones, sino de un sistema estructurado alrededor del oro y la plata, valores materiales que son la fuente de la legalidad y la sacralidad. A ellos sirven las personar

Así resume Guamán la catadura de los actores de esta tragedia: "Se embarcaron al reino de las Indias del Perú, y no quisieron descansar ningún día en los puertos, cada día no se hacía nada sino todo era pensar en oro y plata y riquezas de las Indias del Perú; estaban como un hombre desesperado, tonto, loco, perdidos el juicio con la codicia de oro y plata, a veces no comían con el pensamiento de oro y plata, a veces tenfan gran fiesta pareciendo que todo oro y plata tenía dentro de las manos asido como un gato casero cuando tiene el ratón dentro de 
las unas, entonces se huelga, y si no siempre acecha y trabaja y todo su cuidado y pensamiento se le va alli hasta cogerlo no para y siempre vuelve allf así fue los primeros hombres no temió la muerte con el interés de oro y plata, peor son los de esta vida los espafioles corregidor, padre encomenderos, con la codicia del oro y plata se van al infierno" (374). El sentimiento dominante de esta pintura es el desprecio. Unos seres asf son temibles, no reparan en nada, ni siquiera los detiene el miedo a morir ni el escrúpulo de asesinar, son incontrastables. Pero carecen de dignidad, han perdido los atributos humanos, son peor que animales. Con seres asl no cabe la reciprocidad de dones. Pero es que una pasión asi es tan devoradora que ni siquiera permite que se estabilice la vida Acaba en la muerte. Y para Guamán la muerte no es el lin: van al infiemo.

No estamos aqul ante un cronista ni ante la mente infantil de un ser primitivo que es incapaz de penetrar en los móviles y el corazón de una cultura superior que coma contacto con la suya. Hay aquí un juicio profético, que abstrayendo la brillante superficie de la historiografía oficial (que por otra parte conoce), es capaz de sacar a la luz la figura que ella recubre de gloria. Naturalmente que él sabe que hay otros elementos y móviles en estos personajes, pero ell intuye certeramente que su pintura es el revés de la trama. Y más aún, que su juicio coincide con el juicio de Dios, del Dios que ellos llaman su Dios, el Dios de los cristianos.

\section{EI (des) encuentro}

\subsection{Los embajadores}

El encuentro entre ambos mundos acontecería, según Guamán, en dos etapas: la primera, la de los embajadores, es la fase de los tanteos; en la segunda, el encuentro es un choque frontal. La caracteristica del encuentro es la asimetria.

El primer encuentro se produce en el puerto de Túmbez. Cada inca manda a su respectivo embajador. Aunque estarian en tierra de Atahualpa, el primero en acudir en este ordenamiento jerárquico que instaura el autor habría sido el embajador del Cuzco. El y los dos jefes espantoles "se hincaron de rodillas y se abrazaron y se dieron paz, amistad, con el emperador, y le honró y comió en su mesa, y hablaron y conversaron; y le dio presentes a los cristianos, así mismo le dio al (...) que fue primer embajador que de Atagualpa Inga" (376). Desde los esquemas indígenas de reciprocidad, un acto así no puede significar vasallaje, pero sí reconocimiento y, por lo tanto, una mano tendida en son de amistad. Naturalmente que también significa manifestación de la propia potestad y petición de reconocimiento, y por lo tanto, en caso de ser aceptados los dones, seguridad de que viene en son de paz. Sin embargo, como veremos, no es esa la interpretación de Guamán. Para él, la embajada de Huáscar llega a significar la entrega del reino a los espafioles. Pero este hilo juridico de la historia, interpretativo, 
coexiste con el hilo anecdótico. En él lo más que cabe pensar es en una alianza con los extranjeros para vencer a Atahualpa, ya que no podí contar con muchas lealtades internas y veía su causa perdida.

Desde luego que en el fondo late el miedo de qué pretenderán estos hombres armados que desembarcan a una tierra que no les pertenece y adonde no fueron llamados. La embajada, la honra y los presentes son una especie de conjuro o exorcismo, una invitación implícita para que se vayan. Estas intenciones se hacen explícitas en la embajada que envia Atahualpa: "Le envió suplicando que se volviesen los cristianos a sus tierras y le dijo que le daría mucho oro y plata para que se volviesen, y no aprovechó y dio la respuesta diciendo que quería ver y besar las manos al rey Inga, después se volverian, y que venía por embajador de su rey emperador y así vino adelante" (380). Asl, pues, los incas con su cortesania y sus dones suplican una retirada en paz; pero los espafioles, aunque aceptan el esquema formal, fuerzan la puerta y siguen adelante. No hacen demostraciones de hostilidad, su pretensión explícita (besar las manos al rey inca como embajadores del emperador) aún puede ser encuadrada dentro de los cauces del respeto y reconocimiento. Pero la resolución de los espaftoles llena de recelo a los indígenas.

\subsection{Mala nueva-buena nueva}

Atahualpa está en los baños de Cajarnarca Los espafioles acampan frente a la ciudad. Estan ambos grupos frente a frente. ¿Cómo se ven? "Como tuvo noticia Alagualpa Inga y los señores principales y capitanes y los demás indios, de la venida de los espaftoles se espantaron" (381)."Oída esta dicha nueva se espantó el dicho Inga y le dijo: qué nueva me traes, mal mensaje; así quedaron espantados con la nueva oída y así mandó Alagualpa Inga que le diesen servicios de mujeres a ellos y a sus caballos" (id). Con los mensajeros suplico "muy mucho que se fueran y tomaran y no hubo remedio, que importunó los cristianos verse con la majestad del Inga" (id). La caladura de los cristianos, su talante y resolución son para los indígenas mala nueva, una nueva nunca oída, pero funesta. Por eso no causa paz y alegria, sino espanto. No son, pues, portadores de evangelio; por el contrario, ellos son mala noticia. Noticia no de salvación, sino de perdición.

Los españoles por su parte no mandan servicios. Hemando Pizarro y Sebastián Benalcázar, armados y empenachados y montando caballos enjaezados y acorazados, imumpen al galope en los baflos del inca en un alarde de fuerza. Aquello "le espantó al Inga y a los indios (...) con el espanto cayó en tierra el dicho Alagualpa Inga de encima de las andas (...) cada uno se echaron a huir porque (...) andaban turbados" (383). Al regresar al campanento dijeron los caballeros: "albricia hermanos míos ya yo tengo convencido y espantados a los indios, será Dios servido que le comencemos la batalla; por todos se espantaron y 
dejaron en tierra a su rey y cada no echaron a huir, buena sefla, buena sefia" (id.). Para los espanoles es buena nueva el desconcierto y la debilidad de los indigenas. Es señal cierta de que en esas condiciones podrán derrotarlos. Los indrgenas tratan de convencerlos de que se vayan a fuerza de presentes. Los espafoles tratan de vencerlos con la fuerza aplastante de su apostura y de sus armas. La buena nueva de ver despavoridos a los indigenas está interpretada por ellos en clave cristiana como evangelio: Dios será servido con su derrola. Se trata pues de un dios tribal: servirle es prevalecer sobre otros pueblos. En este esquema, el evangelio para los españoles no puede ser más que mala nueva para los indigenas. No cabe un evangelio compartido.

\section{No caben dos emperadores}

Por fin llega el encuentro. El acto consta de dos partes. Tiene lugar en la plaza pública de Cajamarca, el inca está rodeado de su corte, sus capitanes y cien mil indios. En primer lugar, Pizarto y Almagro dan su mensaje: "dijo que era mensajero y embajador de un gran señor y que fuese su amigo que sólo a eso venía (...); responde el Inga con una Majestad y dijo que será la verdad que tan lejos tierra venían por mensaje, que lo crela que será gran seffor pero no tenía que hacer amistad que también que era él gran seftor de su reino" (385). La propuesta de los españoles, comedida en la forma, dernanda sin embargo, un acto de vasallaje. Por eso responde el inca que el monarca espaniol se atenga a su tierra como el se contiene en la suya. El cree que el rey de Castilla será el máximo en su ámbito de influencia, pero también él lo es en el suyo. Este es el fondo de la cuestión: la pretensión espafiola de incluir a los incas en su área de influencia choca frontalmente con la autocomprensión inca de ser seffores de su imperio. No caben dos emperadores; la propuesta espanola significa que los incas dejen de ser lo que ellos creen ser por designio divino y capacidad probada. Las cartas están sobre la mesa: no se trata de reciprocidad de dones, sino de intercambio, desigual. Pero los indigenas estón en su tierra y no sólo no han dado motivo de agravio, sino que no han cesado de honrar y enviar presentes. ¿Cómo desatar legitimamente las hosilidades?

\subsection{La guerra santa}

Entonces tiene lugar la segunda parte del encuentro: "entra con la suya fray Vicente llevando en la mano derecha una $\dagger$ y en la izquierda el breviario, y le dice al dicho Atagualpa Inga que es también embajador y mensajero de otro seficr muy grande amigo de Dios y que fuese su amigo y que adorase la cruz $†$ creyese el evangelio de Dios, y que no adorase en nada, que todo lo demás era cosa de burla - responde Atagualpa Inga, dice que no tiene que adorar a nadie sino al sol que nunca muere ni sus guacas y dioses, también tienen en su ley, aquello guardaba" (id.). Es el mismo esquema: el imperialismo político-militar se corra con el imperialismo religioso. El embajador del otro sethor muy 
grande amigo de Dios ofrece tambiên amistad a cambio de vasallaje religioso. En este caso, la argumentación es más brutal aún: no trata de convencer al inca de la conveniencia de su propuesta religiosa, no le predica ninguna buena nueva, ningún evangelio; simplemente le declara sin ninguna prueba que su religión es cosa de burla y que por lo tanto tiene que aceptar la que se le presenta Como vemos, la palabra evangelio en boca del misionero cristiano está aquí absolutamente despojada de su tenor literal, designa únicamente un contenido dogmálico ininteligible para el indigena. Como se echa de ver, evangelio signilica, en este caso, para los indígenas, la mala propuesta de que renuncien a sus tradiciones religiosas (a las que se declara sin más sin valor) y que abracen otras que no entienden. De ahí la sensalez de Atahualpa al pedir pruebas. La prueba que presenta el fraile es el libro que llevaba, que identifica con los evangelios. Atahualpa lo toma entre manos, lo hojea y lo deja caer, contrariado por lo que no puede entender sino como una burla: "cómo no me lo dice ni me habla a mf" (id.). Y en efecto, era una terrible burla, un ofensa al inca y sobre todo al Dios cristiano y a los santos evangelios. Es la negación del encuentro de gracia que significa la vida de Jesús: él viene a salvar lo que se habia perdido, a reunir a los hijos de Dios que estaban dispersos, a llamar a las ovejas distantes que no están en su redil y lo hacen con su acercamiento humano desarmado, con sus palabras sencillas y misericordiosas, ensentando largamente con toda paciencia el misterio del reino de Dios que se acerca como una semilla pequefla, como él, que se siembra en la historia humana desde abajo para que gemine lentamente hasta llegar a dar frutos. No era éste el evangelio del fraile. Se trataba de una burla; pero no era una chanza inocente, era un pretexto para romper las hostilidades con la conciencia medio tranquila.

La burla del fraile se hace sarcasmo al calificar la acción del inca como sacrilegio que merece la muerte: "Fray Vicente dio voces y dijo: aquí caballeros, con estos indios gentiles son contra nuestra fe y don Francisco Pizarro y don Diego de Almagro de la suya dieron voces y dijo salgan caballeros estos infieles que son contra nuestra cristiandad y de nuestro emperador y rey demos en ellos y asf luego comenzaron los caballeros y dispararon sus arcabuces y dieron la escaramuza y los soldados a matar indios como hormigas, y de espanto de arcabuces y ruido de cascabeles y de las armas, y de ver primer hombre jamás visto, de estar lleno de indios la plaza de Cajomarca se derribo las paredes del cerco de la plaza de Cajamarca y se mataron entre ellos" (385-86). En la versión de Guamán fue el misionero quien reclama al brazo secular para castigar a los paganos contumaces que acaban de demostrar públicamente que están en contra de la fe cristiana. El resultado de este celo divino es una verdadera hecatombe. Es obvio que la fe aquf invocada no puede ser la de Jesús de Nazarel que murió por las auloridades de un imperio a las que le entregaron las autoridades religiosas de su propio pueblo. La cruz del torturado se ha invertido trágicamente, convirtiéndose en espada de exterminador. Quien un momento antes pedla al inca 
reconocer la cruz del torurado se conviene en la voz colérica que pide vengar al corturado con la muerte de unos pobres agraviados, asustados e indefensos. ¿Qué divinidad se esconde entonces tras la figura de Jesús, usurpando su representación? La de "nuestra cristiandad y nuestro emperador y rey". El dios feroz de una tribu que sólo admite sumisión o muerte, y que, en definitiva, busca la sumisión como camino hacia el oro y la plata. En esa formulación, el emperador es interior a la cristiandad, una de sus cabezas visibles, y la cristiandad es a la vez una magnitud política, étnica, y religiosa. En este caso, la cristiandad designa a un pueblo histórico sacralizado. Y en efecto, el inca habla declarado que no quera servir a ese rey ni a sus dioses. Ese dios mortal, ese Leviatán de la cristiandad ibérica, por su misma condición mortal, no podía permitir el desacato, Lenía que verificarse como incontrastable. Por eso, requería la sumisión y emplazaba con la muerte y necesilaba el oro para mantenerse incontrastable. Por eso, efectuada la prueba de fuerza, el resultado de la hazafla promovida por el celo religioso es la desposesión del inca: "y así, sí le prendió don Francisco Pizarro y don Diego de Almagro al dicho Atagualpa Inga de su trono le llevó sin herirle y estaba preso con prisiones y guarda de españoles junto del capitán don Francisco Pizarto quedó muy triste y desconsolado y desposeído de su majestad asentado en el suelo su trono y reino" (386).

\subsection{Murío mártir cristianísimamente}

No se trató, pues, de ningún encuentro, no interesaha el inca ni su reino, ni sus instituciones, ni su cultura. No sólo faltó interés humano, ni siquiera se dio curiosidad, ni siquiera eran capaces de ver lo que se mostraba ante sus ojos. Concluida la representación apareció brutalmente el único centro de interés: "estando preso le robaron toda su hacienda don Francisco Pizarro y don Diego de Almagro y todos los demás soldados y espatioles, y lo tomaron toda la riqueza del templo del sol y de Curicancha y de Uanacauri, muchos millones de oro y plata que no se puede contar" (388).

Mientras los espantoles andaban locos tras el oro, Alahualpa como ser humano conciente de su tragedia, sufría y se aquilataba en el dolor. "como se vido tan mal tratamiento y dafio y robo tuvo muy gran pena y tristeza en su corazon, y lloro y no comió, como vido llorar a la sefiora coya, llor6, y de su parte hubo grandes llantos en la ciudad de los indios" (388). Guamán subraya el contraste entre la deshumanización de los espajoles que acaban con todo para tener más oro y los indigenas que entonan endechas, yaravies, ante el infortunio del inca y el reino. Más aún, Atahualpa en su cuativerio no pierde la compostura que se debe a sf mismo y la relación humana con sus carcelereos. El se mantiene en su horizonte de reciprocidad de dones: "estando preso conversaba Atagualpa Inga con don Francisco Pizarro y don Diego de Almagro y con los demás espantoles, y jugaba con ellos en el juego de ajedrez que ellos les llaman taptana, y era muy pasible principe y asf se contentaba con los cristianos y daba su hacienda y no 
sabía con qué contentarlos y regalarles" (388). Al fin, la insaciabilidad de los españoles pareció encontrar una medida: como rescate por su vida Alahualpa llenó de oro una estancia hasta la altura que Pizarro señalo con su espada. Pero no fue asf: "Atagualpa Inga fue degollado y sentenciado, y le mandó cortar la cabeza don Francisco Pizarro (....) murió mártir cristianísimamente; en la ciudad de Cajamarca acabó su vida" (391).

El desencuentro acaba en el asesinalo. Quien muere manteniendo su justicia y su dignidad, sin querer abandonar el sistema de reciprocidad de dones y muere a manos de unos idólatras insaciables que lo inmolan a su ídolo, muere mártir; y según Guamán, no mártir de una causa cualquiera, sino de aquella por la que fue asesinado Jesucristo: murió mártir cristianamente. Este juicio del indígena cristiano Guamán Poma revela la entrafia de esta representación sagrada: el indígena gentil e idólatra muere cristianamente, mártir. Por lo tanto, sus asesinos son los que tienen odio al cristianismo. Estos, que odian el nombre cristiano hasta asesinar a quien lo proclama con su vida, son quienes a sí mismos se llaman cristianos y que arribaron ante el inca enarbolando la cruz y el evangelio. Esta es la paradoja que proclama Guamán: el testigo de Jesús fue el inca Los cristianos desconocieron tanto a Jesús, se entregaron de tal modo a sus f́dolos, que asesinaron a su testigo.

Este juicio de Guamán sobre la muerte de Atahualpa es congruente con el sistema de valoración que atraviesa su Crónica Indígena. Insistiamos al analizarla en el modo sistemático cómo llama cristianos a los indígenas, basado en, el criterio de su praxis congruente con la ley del evangelio y las obras de misericordia. Decíamos que Guamán valora la revelación cristiana, pero consecuentemente con ella, sitía a la praxis como el criterio definitorio. Precisamente él sabe eso por haber recibido la revelación cristiana. Por eso la aparente paradoja, cristianamente comprensible, de que un gentil muera mártir cristianamente a manos de unos que a sí mismos se llaman cristianos y que al mararlo creen dar culto a Dios. "No se puede servir a Dios y al dinero", decía Jesús, y para Guamán ese es el caso de los espafioles: "vosotros tenéis ídolos en vuestra hacienda y plata". Por adorarlos niegan a los hijos de Dios y niegan a Dios. "Paréceme a mi, cristiano, todos vosotros os condenáis al infierno" (367). La muerte de Atahualpa como mártir cristianísino es la prueba concluyente de que para Guamán él es el representante espiritual del mundo indigena; en él culmina esa historia cristianamente ascensional, a pesar de la idolatría inca, su muerte hace ver que esa idolatria no era un mal tan grave que impidiera la realización cristiana.

\section{El derrumbe}

El derrumbe de los muros de la plaza de Cajamarca es el símbolo del desplome del mundo indrgena o por lo menos constituye un cambio de signo de esa historia ascendente en vida material, policla y obras de misericordia, hacia un 
tiempo de postración, miseria, opresión y alienación que todavía dura cuando escribe el aulor; que precisamente escribe para enderezarlo volviendo a anudar con el esplritu y la ley perdidos, en definitiva con el sistema de reciprocidad de dones.

\subsection{Continuidad}

En este punto, el autor necesila hilar fino. En efecto, por un lado, se empefia en mostrar que no hubo conquista porque los indígenas no se defendieron. Según este esquema, no habría habido resistencia amada, sino entrega del imperio a los wiracochas. Desde este punto de vista no existiría ningún corte, sino continuidad. Para eso le sirve su insistencia en la legitimidad de Huáscar y el sentido de su embajada. Asf́ lo asienta enfálicamente en su crónica de los reyes incas: "en este dicho Uáscar Inga se acabó los reyes y Cápac Apo Inga legítimo por la ley del Perí de este reino, y dejó la borla y mascapaycha y Corona a Nuestro Sefior y Rey Sacra Católica Majestad, el que manda todo el mundo" (117). "No se defendieron los indios que se dieron luego a la Corona Real de Su Majestad" (162, ver 386, 393, 395). Incluso llega a decir eso mismo de Manco Cápac: que se retiró a Vilcabamba "y dejó el reino y corona, mascapaycha y chambi, al sefor emperador y rey nuestro seffor" (406).

Esta insistencia de Guamán en la continuidad jurídica, que haría de los monarcas espantoles verdaderos sefiores naturales, es fundamental en su esquema ya que en ella se basa para poder exigir el reconocimiento de los derechos tradicionales, ya que según el sistema de reciprocidad andino, concordante en esto con el pacrimonial de los reyes de Castilla, los que se entregaban libremente conservaban sus fueros, y el sefior que aceptaba constituirse en su señor juraba por su parte respetar las leyes y la idiosincracia de aquellos que recibia como vasallos. No solamente esto. El señor podía pedir y pedía servicio a sus vasallos y en cada caso se suscribían acuerdos según las necesidades del señor y las posibilidades de los súbditos. Pero los vasallos libres no pagaban tributos. Eso era propio de los siervos o de los vencidos. Guamán veía certeramente que el punto de los tributos era el que decidía del buen ser 0 la decadencia de los indígenas y de su mundo. Por eso su teoría de la continuidad, que casaba bien por otra parte con la ideologia de los reyes de Castilla, era piedra angular para sus propuestas de buen gobierno. De ahł también el interés, al que nos referimos antes, para establecer que en tiempo de los incas, antecesores de los reyes de Espafta "no pagaba tributo" mientras que "ahora dice tributario quiere decir esclavo en gran dafio de los pobres cristianos indios". (338, ver 339).

\subsection{Los cuatro jinetes del apocalipsis indígena}

Pero si a nivel jurídico puede sostenerse la teoría de la continuidad, a nivel emplrico lo que se constata es el derrumbe. Todo se descompone y acaba cuan- 
do se sale de sus cauces, ya que esas "calles" tradicionales eran los caminos que mantenian la vida de cada quien en el cuerpo social y en el delicado equilibrio de ecosistemas que tan laboriosamente habían creado. En primer lugar, se abandona al señor natural: "estando preso Atagualpa Inga todos sus vasallos e indios y capitanes y sefiores grandes de su reino le desampararon y no le sirvieron" (388). En segundo lugar, con la codicia del oro, los españoles acabaron con la aristocracia indígena: "mató a los dichos Ingas y a todos los sefiores grandes y capitanes generales, y a los principales de cada provincia de este reino con varios tormentos, pidiéndole oro y plata, y trala presos y lo castigaba muy cruelmente preso con cadena de hierro y de cuero de vaca torcido" (397). En tercer lugar, hubo pueblos indígenas que según Guamán se pasaron a los espafioles no por servirles, sino para robar con ellos: "los cañaris y chachapoyas y yayaconas se metieron sólo a fin de robar y hurtar con los dichos espanjoles, no se metieron por servir a Su Majestad" (395). Más aún, los salteadores que merodeaban en los sitios más fragosos e inaccesibles se hicieron pasar por aliados de los espanoles para hacer sus fechorias impunemente; "andaba en las quebradas hondas y pedregales y peñas barrancas (...) y salteaba por los caminos reales estos dichos indios cimarrones; estos dichos salteadores, pomaranra, en tiempo de la conquista se hicieron yanaconas, de los dichos espafioles y salteaban mucho más mejor y robaban a los pobres indios, y despues se quedaron y se visitaron en las ciudades" (397). En cuarto lugar y lo más grave fue la conducta de los espantoles: "se derramaron por todas las partes de la tierra de este reino de dos en dos, y algunos cada una, hay cada gente yanaconas indios buscado cada uno sus ventajas, y buscando remedios, haciendo muy grandes males y daftos a los indios pidiéndoles oro y plata, quitándoles sus vestidos y comida, y los cuales se espantaron por ver gente nueva nunca vista y así se escondían y se huían de los cristianos de todo el reino" (395). "Después de haber conquistado y de haber robado comenzaron a quilar las mujeres y doncellas, y desvirgar por fuerza, y no queriendo le mataban como a perros y castigaba sin temor de Dios ni de la justicia ni había justicia" (id.). Y como el botín parecía infinito se embarcaron muchos para proseguir con los mismos mélodos el saqueo: "Con la codicia se embarcaron muy muchos sacerdotes y espafioles y sefioras mercaderas para el Perú, todo fue Perú y más Penú, Indias y más Indias, oro y plata, oro y plata, de este reino" (391). Y no sólo las personas particulares, según Guamán, también fue esa la pretensión y el propósito del rey y los funcionarios: "por la riqueza envió el emperador gobernadores y oidores, presidentes y obispos y sacerdotes y frailes y españoles y señoras" (id.).

\subsection{Perdidos de sus dioses y señores}

Para el autor, el cataclismo se debería al descabezamiento que hacen los espafioles de las jerarquías del reino y al mal ejemplo que ellos dan de saltarse todo los cauces y pretender grandezas y señorlos que no les correspondian; mu- 
chos indígenas siguen su ejemplo, y se pierde todo respeto y toda norma, y las "calles" ancestrales se rompen y cada quien mira por si pretendiendo todos reinar y nadie servir. "ahora todos son ingas y reyes, los espaftoles" (337) y los indigenas los imitan "este es decir que hay mundo al revés, pero la justicia debe ajustar y castigar" (409).

Es una sibuación de anomía por haberse derrumbado un orden y sus regentes y no haber entrado los que le sucedían: "los indios andaban perdidos de sus dioses y uacas y de sus reyes y de sus sefiores grandes y capitanes en este tiempo de la conquista ni habia Dios de los cristianos ni rey de Espanta ni había justicia (...) y asf hubo muy mucha hambre y alboroto y se murió mucha gente y revuelta en todo reino daca oro y toca oro" (389).

Este lexto revela la profundidad del cataclismo: todos los personajes que servian de punto de referencia para los indígenas, los que simbolizaban el orden del mundo y velaban por él, se habian perdido; los personajes humanos, los seres divinos y los que hacían de puente entre ambos. El indigena es en cuanto participa de ese orden sagrado fundado en una reciprocidad de dones rigurosamente pautada, aunque aceptada internamente como la que dota de sustancia, dignidad, sentido y alegria a la vida Derrumbado ese orden, zen base a qué se define cada quién? Si cada indigena era un participante, ¿qué será cuando no existe ese sisterna de reciprocidad? Por otra parte, los espafioles tampoco instauran ningún orden alternativo. Para ellos, el oro y la plata son los únicos objetivos, aquello que vuelve relativo a todo lo demás. En la práctica, ellos tampoco tenfan Dios ni rey ni ley. Sólo servian al oro y plata idolizados. Y cuando el único Dios es el oro estamos en una situación de muerte, porque el oro es un fetiche insaciable. Los ídolos de los indigenas vivían de la vida de sus adoradores, de los dones que ellos les daban como reciprocidad de los que recibian de ellos. Sin embargo, el fetiche de los espantoles no se alimentaba de sus adoradores: los que le rendian culto se convertian en sacerdotes siniestros, en sacrificadores de víctimas. De ahi, la destrucción del mundo indígena.

Asf pues la conquista es el tiempo del no gobierno: Los conquistadores destruyen el orden de los incas y nada ponen en su lugar. Es la Hora del Poder de las Tinieblas, la noche encamizada de los sacrificadores del demonio del oro, es el tiempo del infiemo. La ficción jurfdica de la continuidad haría posible, piensa Guaman, recomponer los cauces. Pero âun no es el tiempo. Aún hay que apurar la copa hasta las heces. El ciclo del oro debe parir el de la sangre.

\section{La autodestrucción}

\subsection{El ciclo de la sangre}

El ciclo de la sangre venía urdiéndose desde el comienzo: "saltaron en esta tierra; luego comenzaron a tener diferencias (...) y con la codicia de oro y plata 
que ya en su corazón trafan, matarte he o matarme has, y unos y otros se mordian" (376). Por eso, en cuanto derribaron el mundo indígena, que era la contradicción externa que los cohesionaba, se manifestaron las contradicciones internas; o por mejor decir, el mismo impulso desenfrenado que se habla cebado sobre los otros, recayó sobre ellos mismos, destruyéndolos. En una situación signada por una escasez irremediable se explica la violencia para apropiarse de lo indispensable para la vida que no alcanza para lodos. Pero en esa situación de riqueza al parecer inagotable, matarse por no compartirla parece una maldición. Y lo es, en efecto. Es la maldición del demonio del oro que, después de acabar con las víctimas inocentes, destruye a los victimarios. "Con el interes de la conquista y del gobierno del reino, y de la riqueza del oro y plata feble" (409). Francisco Pizarro mato a Diego de Almagro, Almagro el joven mato a Francisco Pizano, Gonzalo Pizarro maló a Diego de Almagro el joven. "No tuvieron contradicción con los indios ningún capitán, sino entre ellos por la codicia de los indios, y del oro y plata y senorear sólo absolutamente, sin que nadie se le meta en este reino sin mandato del seffor emperador". Para perpeuar su situación sefiorial y la encomienda perpetua de indios Gonzalo Pizarro se rebeló contra el rey y mató al virrey y Núfiez de Vela. El presidente La Gasca mató a Gonzalo Pizarro y desbarató su partido. Con él se instaura el orden: "defendió la Corona Real y sirvió a Su Majestad e hizo justicia a los traidores, y entablo la tienra como fiel caballero" (418). Pero entablar la tierra costó mucha sangre en diversos encuentros y en la batalla final, "en la gran batalla que fue mayor en este reino entre cristianos que no con los indios" (423) en que Gonzalo Pizarro quedo desbaratado. Todava se sublevó antos después Hernández Girón. Después de escaramuzas y encuentros fue prendido por unos indígenas " $y$ se hizo justicia en ellos, y las pusieron las dichas cabezas con los demás traidores y se ejecutó en ello y así se acabo la rebelación contra la Corona Real" (435).

En esta última fase son los indígenas quienes contemplan con estupor cómo los lobos carniceros se despedazan entre sI en un frenesI de muerte. La escritura atropellada de Guamán se convierte aquí en una verdadera danza de la muerte medieval. Es la muerte la que campea, la que gana todas las batallas, la que desposa a cada uno de sus hijos entre el vértigo y la insania y al fin son los propios indígenas quienes capturan al úlimo de los depredadores; pero no lo tratan como fueron ellos tralados, sino lo entregan a la justicia contribuyendo también ellos a alumbrar el tiempo nuevo. Todo está consumido. La representación ha acabado. "Hasta haber buena juslicia, habia durado veinte y cuatro anos este desasosiego y pestilencia y alboroto de querer de pobre hacerse seftor, no quiso Dios" (435). 


\section{La meditación}

\subsection{No quiso Dios. Defensa de la utopía}

¿Cómo puede entenderse este juicio de Guamán? Veo dos interpretaciones, no necesariamente alternativas. La primera más anecdótica consistiria en el repudio del autor de una situación de movilidad social, su condena a una sociedad abierta y fluida en la que ciertamente caben aventureros y asesinos, pero también se da el estímulo de dar de sí, de crearse a sl mismo, de levantar casa y estirpe, de engendrar riqueza y bienestar y en la que también, finalmente, se impone la justicia. Dios no quiso, según esta interpretación, una sociedad fundada en la valía, el tesón y la ambición; Dios no quiere una sociedad mestiza, sino una sociedad estamental, basada en tradiciones incontrastadas. Este juicio de Guamán se darla desde su pretensión nobiliaria; desde ella repudia cualquier intento igualitario.

La segunda interpretación, que como decíamos nos parece componible con la primera, irfa más al fondo de las cosas e independientemente de lo biogtáfico, nos parece desprenderse de la lógica de su escrito. Sin entrar a sus propuestas en la parte dedicada a El buen gobierno y ateniéndonos a la Nueva Crónica. sí apunta todo a un orden que tiende a ser repetitivo: el ciclo de los meses con sus actividades pautadas, las calles por las que trascurren los años de cada una de las generaciones, las visitas semestrales de las autoridades... todo se toma genérico, impersonal, por repetirse muchas veces en la vida de cada persona y al sucederse en cada una de las generaciones. Sólo parecen avanzar las conquistas de los incas, las fundaciones de pueblos y grandes ciudades, la construcción de nuevos andenes, el avance de los canales de riego y de los caminos reales... ¿Cuál es la razón de ser de este orden? Ante todo la precariedad de los ecosistemas que exige el concurso ordenado de los esfuerzos de toda la sociedad para mantenerlos y perfeccionarlos. Cualquiera que conozca un poco del hábital del Tawantinsuyu tiene que reconocer que la razón es de muchísimo peso. Pero la razón de fondo es el tinte utópico del escrito de Guamán. Para él, la respuesta que los indígenas han ido creando a lo largo de un tiempo muy dilatado y con el concurso de esfuerzos encadenados a través de las distintas edades es una respuesta ejemplar. La Nueva Crónica es narración, incluso muy anecdótica; pero es sobre todo la plasmación genético-estructural de un diseffo utópico, que, sin embargo, ha ido haciéndose camino y edificando lugar, es decir, que no es un modelo imaginativo, una representación ideal, obtenida por contraste con la realidad, sino que es la comprensión quintaesenciada de algo que tendencialmente existe, pero que puede y debe dar mucho más de st.

¿Es vivible ese orden con el aumento de la conciencia de sf? Para el autor, la respuesta es cieramente afirmaliva porque, a pesar del esquemalismo generaljzante, el contenido del sistema es la reciprocidad de dones, un contenido emi- 
nentemente personalizador. Desde luego que no admite altemativas: sino se quiere vivirlo desde su entraña se le presionará para que lo viva por coacción. Pero cabe el florecimiento de la individualidad excelsa que se realiza personalizadoramente en la entrega al grupo, que el grupo retribuye con honra, colaboración económica y reconocimiento social.

La propuesla de Guamán es que dentro del régimen español cabe realizar la ulopía andina y que esa propuesta a la larga le conviene también al rey, si se comporta como seflor natural. Claro que para eso son necesarios cambios bien radicales. A eso va El buen gobierno, aunque, como llevamos dicho, las líneas maestras están ya trazadas en la Nueva Crónica.

\section{Contra el mestizaje desde el mestizaje}

¿No es contradictorio que esta propuesta la sustente precisamente quien a sí mismo se llama don Felipe Guamán Poma de Ayala y quien llega a firmarse Felipe de Ayala? Si la fima es una expresión profunda de la propia identidad, en este caso, en que no es simplemente heredada sino compuesta por el autor, elegida por él, simboliza la pretensión de una identidad como proyecto que aspira al reconocimiento. Guamán Poma pretende emparentar con la aristocracia preinca del Chinchaysuyu y con la realeza inca. Felipe de Ayala se cobija a la sombra de un conquistador leal al rey, de un vecino señalado por los servicios que merecen mercedes. Guamán Poma y Felipe de Ayala son la misma persona. Independientemente del sustrato racial, que muy probablemente es únicamente indigena, esta identidad compuesta es una identidad mestiza. En sus dibujos él se representa no sólo con vestidos de espantol, sino con facciones espantolas. Pero es su escritura la que nos descubre más profundanente su fntimo proyecto vital: pretende escribir en espanol, aunque no lo domina y el sustrato indígena aflora constantemente. Pero no es sólo esa transición entre lo que quiere ser y lo que todavía es. El no pretende llegar a españolizarse. También escribe el quechua, no sólo porque no encuentra traducción exacta, sino porque quiere perpetuar la nomenclatura, las expresiones más entranables y definitorias, oraciones, fórmulas rituales y hasta canciones. Mestizo es también su contenido: desde su condición fervorosa de cristiano nuevo defiende el cristianismo de los indigenas gentiles y hasta de los idólatras; desde su contribución casi policial en la campana feroz de estipación de idolatrías asienta vigorosamente la legitimidad de usos considerados idolátricos por los visitadores; desde su adhesión leal a la corona de Castilla defiende el orden indígena como su modelo utópico; desde su participación en la administración colonial denuncia implacablemente no sólo sus abusos, sino los usos que considera injusios. Guamán personalmente es un ejemplar sobresaliente de lo que significa un mestizo en su más hermosa posibilidad: un mediador entre dos mundos, que aceptando cordialmente y llevando en sf a cada uno de ellos, como imperceptiblemente, va dando a luz uno nuevo sin pretender sustituir a los otros ya constituidos, sino fecundándolos con sus aportes 
concretos y sobre todo manteniendo abierta la mutua respectividad.

¿Por qué una persona así se pronuncia constantemente contra el mestizaje y los mestizos? Habria, pienso, dos razones. La más explícita es que los ve como gérmenes de anomía No podía ser de otro modo desde su concepción utópica: las utopías son siempre estáticas y acaban suprimiendo la libertad. Por eso, del evangelio, no puede sacarse ningún modelo imaginario que pudiera hacer las veces de una utopía. El evangelio sólo propone una historia, siempre ambigua, abierta a la trascendencia y transida por ella, pero sin figuras institucionales sagradas. La trascendencia sólo se da en aclos y sacramenlos; las personas, los sistemas, las estructuras y las instituciones son siempre historicas, es decir, abiertas, inacabadas, ambiguas, capaces de conversión y recaída, de perfectibilidad, estancamiento y derrumbe, de gracia y de pecado. El mestizo como proyecto que es, como mediación por la que se define, es lo que más se parece al talante histórico. Es, pues, lo menos adecuado para una utopía.

Y aquí viene la segunda razón. Precisamente, Guamán se coloca fuera de ella El es el que la posee; él, pues, es como el filósofo platónico, el episcopos, el que inspecciona desde arriba la buena marcha de todo, su cumplimiento. Es como los misioneros que disenaban para los indígenas mundos ordenados, inocentes y cerrados, que ellos controlaban con su conciencia alerta, sentida como paternidad responsable. Ese es el peligro del mestizo: el deslizamiento sutil, realizado a espaldas de su conciencia, de su papel de mediador al de intermediario asimétrico entre el mundo de los dominadores y el de los dominados. Llegado a ese punto, él no comparte horizontalmente con ninguno de ellos; trata de aprovecharse de los dominadores, aunque necesite transarse para conservar su órbita de influencia; y se desvive en favor de los dominados, pero reservándose la información y el poder, vive para ellos, pero no con ellos. Guamán está aquí más cerca de lo que él quisiera del esquema de muchos de los más abnegados misioneros, defensores acérrimos como él del modo de vida indigena, pero padres y caciques celosos, amorosos y eficacísimos, y no simplemente hermanos y servidores de su proceso abierto de crecimiento.

\section{3. ¿D6nde estaba Dios?}

El tiempo de la conquista es para Guamán el tiempo del mal gobiemo o peor aún del no gobiemo, de la anomía. La culminación de la falta de norma y auloridad es para nuestro autor la ausencia de Dios: "en este tiempo de la conquista ni había Dios" (389). Con esta expresión tremenda, Guamán quiere decir que los espatioles no fueron portadores de Dios, no hicieron presente a su Dios, comportándose como hijos suyos; por el contrario, con sus obras negaron a Dios: "y si negáis a Dios - los apostrofaba Guamán- lo negais a pie juntillo" (367). Con frecuencia alude a que los espafioles obraban sin temor de Dios y su consecuencia o manifestación es la falta de justicia, el irrespeto a la vida y a la dignidad inaliensble del indigena como persona humana. Y por otra parte, aún no habian 
recibido los indígenas la buena nueva de ese Dios; no había, pues, tampoco Dios para ellos como fuente de fortaleza, dignidad, esperanza y consuelo. Sin embargo, que no estuviera Dios en las conciencias de los seres humanos en tiempo de la conquista no significa que Dios se hubiera eclipsado de improviso. Ausente de las conciencias, estaba presente en la realidad de esa historia. ¿Dónde estaba Dios? Por un lado, torciendo los designios de los conquistadores; por eso cuando rodó su última cabeza y fue expuesta con las demás al escamio público y así se cerro el ciclo y desaparecieron, recapitula el autor. "no quiso Dios". Parecían lodopoderosos, dioses de la guerra y de la muerte, y además invocaban el nombre de Dios y de sus santos para que les favorecieran en sus hazafias criminales. $\mathrm{Y}$ al parecer Dios estaba con ellos, porque triunfaban en todo. Sin embargo, al fin se vio claro que su destino trágico era el juicio que Dios pronunciaba sobre su obra. Pero, como siempre, Dios estaba haciendo un juicio, un juicio paradojico: los que se crelan del bando de Dios murieron en sus pecados; los que parecían perdidos y ciegos, unos murieron en el Seflor y otros fueron preservados por él de la catástrofe. En efecto, al "no quiso Dios" aplicado a los conquistadores, se opone el "murió márir cristianamente" referido al rey inca. El mártir es el testimonio más clamoroso de la presencia de Dios que vence sobre la prepotencia de los opresores y sobre la debilidad de los oprimidos. Así, pues, para Guamán, ese tiempo de pachacuti, de cataclismo, del castigo destructor, del imperio de los fetiches del oro y de la sangre es más aún un tiempo pascual: Dios pasa desbaratando los planes de los que se creían del pueblo de Dios, de los que decian obrar en defensa "de nuestra cristiandad y nuestro emperador", y manifiesta su gloria en el pagano inocente ajusticiado y en lodos los indígenas que no se entregaron al vandalismo, sino que conservaron su dignidad en medio de la calamidad.

\subsection{Permisión de Dios}

Y sin embargo, Dios sabe sacar bienes de los males: "en este tiempo salieron los hombres Uiracochas cristianos en esta revuelta de este reino, $y$ fue ventura y primición de Dios que tanta batalla y derramamiento de sangre y pérdida de la gente de este reino saliesen los cristianos; fue Dios servido y la virgen adorada, y lodo los santos y santas, ángeles, llamado de que fuese la conquista en tanta revuelta de Huáscar y Atagualpa ingas" (378). ¿Por qué fue ventura y permisión de Dios? Puede ser que asi se evitó el derramamiento de sangre de una conquista que tiene que hacer frente a una tenaz resistencia armada. Puede ser que asf los espantoles pudieron tomar el imperio y con esta ocasión convertirse los indios al cristianismo. Puede ser que asi los indigenas se entregaron y de este modo pueden por una parte acceder al cristianismo y por otra conservar sus fueros. cosa que no hubiera ocurrido caso de haber sido vencidos en la guerra de conquista. Creemos que Guamán piensa en todo esto y sobre todo en lo último. As lo confirman otros textos: "fue servido Dios que en este tiempo enviase su cm- 
bajador y mensajero el rey emperador (...) y así fue conquistado y no se defendio" (386). "En este alboroto saltaron de Castilla a este reino los españoles y no se defendieron los indios como los indios de Chile y se dieron al servicio de Dios y de la corona real de Su Majestad los señores indios de este reino" (117).

Guamán puede comprender el alzamiento de Manco Cápac sin romper su lógica ya que sería el vasallo que se rebela legítimamente contra su seffor por los agravios de éste. También dentro del derecho castellano es ésta una posibilidad reconocida: "se alzo contra ellos por los malos tratamientos y burlas que se chocarreaba del Inga y de los demás seffores de este reino, a vista de ojos le tomaban sus mujeres e hijas, y doncellas con sus malas opiniones y con poco temor de Dios y de la justicia, y de que recibian otros muchos agravios que le hacían a los indios; y así se defendió" (399). Pues bien, aunque Guamán subraya sin ninguna ambigluedad la legitimidad de esa defensa, el inca tiene que retirarse a Vilcabamba, puesto en fuga no por soldados espafioles, sino por seres celestes que combaten por ellos. Primero intenta quemar la estancia donde los espafioles se habian relugiado que era el recinto que ellos habian dedicado como templo, y la casa no se quemó y el fuego no quiso tocar la cruz que ahí habia (401). Luego, invocando los espafioles a la Virgen, los indigenas vieron cómo una seffora blanquísima con el vestido más resplandeciente que el sol "le echaba tierra en los ojos a los indios infieles" (403). Y por fin, dando voces los cristianos a Santiago, cayó un tremendo trueno en la fortaleza de Sacsayhuamán: Illapa era Santiago en su caballo blanco que con su espada desbarato el cerco "con gran destrucciơn y muerte, muy muchos indios" (405). "Se desbarató Mango Inga por el sefor Santiago de los cristianos" (406) y se fue huyendo a Tambo y luego a Vilcabamba.

Es esta la parte más ambigua de su interpretación. Desde su perspectiva de cristiano nuevo en la que su fe y su religión son la estructura englobante y el criterio máximo para enjuiciar un acontecimiento no puede dejar de mencionar y celebrar estos milagros. Pero ¿qué queda entonces de su perspectiva indigenista y de su criterio cristiano, de enjuiciarlo todo desde la perspectiva de los pobres? Sigamos sus razonamientos. El milagro de la cruz tiene para el un alcance simbolico que trasciende la coyuntura ya que se refiere al lugar y no a los que lo ocupan: "era sefial de Dios que estaba ya lija la Santa Iglesia en el reino" (401). Por eso subraya "que ellos se espantaron como el fuego no queria llegar a la santa $\dagger$, que fue milagro de Dios Nuestro Sefor en ese tiempo" (id). Dios sentalarfa a los indigenas la sacralidad de la cruz y del templo; y su indestructibilidad serla la seftal de que ya estaba plantada, de que no habrla modo de desarraigar a la Iglesia en el Perú. El mismo sentido tendrfa el milagro de la Virgen: quiso hacer merced "a los espaftoles cristianos, por mejor decir que más quiso hacer merced la madre de Dios a los indios porque fuesen cristianos y salvasen las ánimas de los indios, rogando a su hijo precioso y a la Santusima Trinidad, Dios Hijo, Dios Espiritu Santo, un solo Dios" (403). En lo inmediato, la Virgen favo- 
recía a los españoles, pero su intención era que no se quedasen los indios paganos, sino que, con la presencia de los misioneros, pudieran llegar a la fe y salvación. Así, pues, en ambos casos, estorbar que los indigenas lograran su propósito de echar a los espafioles era un signo de predileccion: la cnuz queria quedarse con ellos y la Virgen ser su madre y que ellos conocieran a su Hijo y adorasen al verdadero Dios. La aparente parcialidad por los espafioles era en realidad predilección por los indígenas.

El caso de Santiago me parce más difícil de encajar en el esquema general, creo que es una contradicción de Guamán o yo no lo entiendo. Una primera diferencia fundamental con los anteriores sería la identificación del apóstol Santiago con una divinidad indígena. Santiago es Illapa. "Se espantaron los indios y dijeron que había caído Illapa (...) y lo vieron al caer en tierra como rayo y así los indios son testigos de vista del seflor Santiago" (405). Una segunda diferencia es que esa divinidad indígena que coincidiría con otra cristiana se presenta "favor de cristianos" (id.). Aquí no hay ambigüedad: favorecer a los cristianos quiere decir matar a más indígenas que el más salvaje capitán español y con su mismo tipo de armas; sólo se distingue de ellos por su mayor prestancia. A pesar de todo ¿resulta tan buena nueva que una divinidad indígena permanezca en la hecatombe que eso compensa todo, ya que también ellos pueden trabajarla para que acabe poniéndose a su favor? Veo a los indígenas llevando a su Santiaguito, sin curas, como cosa suya, y veo a Santiago mataindios en el altar mayor de grandes iglesias y no puedo creer que sea el mismo personaje. Este me parece claramente el ídolo feroz de una tribu conquistadora que se autoentiende como pueblo elegido. Aquel me parece ser el punto (uno de los puntos) en los que el panteón de los vencedores y el de los vencidos se homologan e intercambian atributos, no es el ídolo detrás del santo, más me parece el santo idolizado y el f́dolo "santificado", no sé si sincretismo o más bien simbiosis. ¿Es esto así? De todos modos hasta hoy se ha cumplido lo que prescribe Guamán: "debe guardarse esta dicha fiesta del sentor Santiago en este reino, como pascua" (id.).

De todos modos queda que para Guamán el cristianismo es un gran bien para los indígenas, un bien absoluto. Por eso aunque la mayor parte de los cristianos espatioles hayan sido para ellos como una peste, aún asl puede darse por buena su presencia, por haber dado ocasión de que los indigenas conocieran el cristianismo. Ahora tienen buena ley, pero mal gobiemo. Para eso escribe el autor, para que conociendo bien los responsables el sentido del mundo indígena, pueda llegarse a la síntesis de la buena ley (el cristianismo) y la buena obra (el sistema indígena de reciprocidad de dones), que ya de suyo es buena ley por comprender la ensentanza de Jesús y las obras de misericordia, aunque el autor haya llegado a esta conclusión desde su profesión de fe cristiana. ¿Será posible esa síntesis? 